\title{
LA TRAYECTORIA ITALIANA DE JULIO AQUILES EN EL CÍRCULO DE RAFAEL*
}

\author{
NURIA MARTÍNEZ JiMÉNEZ ${ }^{1}$ \\ Universidad de Granada
}

En este artículo se presentan noticias inéditas sobre la vida y obra del artista italiano Julio Aquiles, pintor formado en el taller de Giovanni da Udine en Roma y colaborador de Perino del Vaga en Génova, que, tras su intervención en los palacios de Francisco de los Cobos y en la Casa Real Vieja de la Alhambra, acabó convirtiéndose en uno de los artistas más influyentes en la pintura mural del Renacimiento en España.

Palabras clave: Julio Aquiles; Giovanni da Udine; Perino del Vaga; Pintura mural; Renacimiento; Roma; Génova; Granada.

\section{THE ARTISTIC CAREER OF JULIO AQUILES IN RAFAEL'S CIRCLE}

The author presents unpublished documents relating to the life and work of the Italian artist Julio Aquiles, a painter who trained in the Roman workshop of Giovanni da Udine workshop and worked with Perino del Vaga in Genoa. In Spain, after his works in the palace of Francisco de los Cobos in Valladolid and in the Casa Real Vieja of the Alhambra, he became one of the most influential wall painting artists of the Spanish Renaissance.

Key words: Julio Aquiles; Giovanni da Udine; Perino del Vaga; Wall painting; Renaissance; Rome; Genoa; Granada.

Cómo citar este artículo / Citation: Martínez, Nuria (2019): "La trayectoria italiana de Julio Aquiles en el círculo de Rafael". En: Archivo Español de Arte, vol. 92, núm. 365, Madrid, pp. 1-16. https://doi.org/10.3989/aearte.2019.01.

Julio Aquiles pertenece a esa generación de pintores italianos que, formados en el círculo de Rafael en Roma, se trasladaron a otros centros artísticos al amparo de las nuevas construcciones patrocinadas por los grandes nobles del Renacimiento.

A diferencia de lo que sucede con grandes maestros como Giovanni da Udine, Giulio Romano o Perino del Vaga, la trayectoria italiana del pintor que protagoniza nuestro estudio es prácticamente desconocida. En cambio, la carrera de Julio Aquiles en España ha sido reconocida por los estudiosos prácticamente desde su llegada.

Desde épocas muy tempranas historiadores y tratadistas han indicado que Julio Aquiles vino a España junto a Alexandre Mayner ${ }^{2}$ para trabajar en los palacios de Francisco de los Cobos y

\footnotetext{
* Trabajo realizado en el marco del Proyecto I+D HAR 2014-52061-PD "La copia pictórica en la Monarquía Hispánica (siglo XVI-XVIII)” dirigido por el doctor David García Cueto y financiado por el MINECO.

1 nuriamj@correo.ugr.es / ORCID iD: http://orcid.org/0000-0003-2479-7598.

2 A lo largo del texto utilizaremos los nombres que aparecen en el cuaderno de nóminas del Archivo del Patronato de la Alhambra y el Generalife.
} 
en la Casa Real de la Alhambra ${ }^{3}$. Con todo, la primera referencia documental se localiza en Valladolid, donde Julio participó en la tasación del retablo de San Benito de Alonso Berruguete en agosto de $1533^{4}$.

Seguidamente encontramos a Julio Aquiles, pintando en la Alhambra. Su nombre aparece en el primer volumen del cuaderno de nóminas de la Casa Real de la Alhambra en marzo de $1537^{5}$ y pocos meses después se indica que "las cuadras ya están doradas". Por tanto, los pintores debieron de llegar antes para organizar e iniciar el proceso ornamental de las habitaciones nuevas.

Según Ceán, los pintores Julio y Alexandre trabajaban en Granada en $1533^{7}$. Esta fecha, que no ha sido advertida por los historiadores es, a nuestro juicio, demasiado temprana ya que, como hemos indicado, en agosto de ese año Julio se encontraba en Valladolid. La ausencia de documentación sobre la decoración del palacio de Cobos y sobre el inicio del ornato pictórico de las estancias imperiales de la Alhambra dificulta el conocimiento sobre el traslado de los pintores ${ }^{8}$ a Granada. Sin embargo, hemos podido documentar la residencia de Alexandre en la ciudad desde $1534^{9}$, por lo que los artistas debieron de llegar a la capital del Darro en torno a esa fecha para trabajar en la Casa Real Vieja de la Alhambra.

Centrándonos únicamente en su labor pictórica en Granada, Manuel Gómez Moreno distinguió la paleta de Julio en las decoraciones de grutescos, bestiones y demás elementos decorativos, mientras que Alexandre se encargaría de la ejecución de las escenas de batallas y de las historias de Faetón ${ }^{10}$. El historiador también constató que, junto a sus tareas como pintor, Julio intervino en la tasación de la escultura de la Fama de Niccolò da Corte, junto con Diego de Siloe y Pedro Machuca en noviembre de $1537^{11}$.

De los cuadernos de nóminas también se deduce que su estancia no fue continuada por lo que pensamos que durante estos años inició la decoración del Palacio de Cobos en Úbeda ${ }^{22}$, ciudad en la que ya residía en $1545^{13}$. Este año supone el inicio la última etapa de su carrera. Un periodo bien conocido gracias a los aportes documentales de Vicente Miguel Ruiz Fuentes ${ }^{14}$ y Juan

\footnotetext{
${ }^{3}$ En estos años se han escrito numerosas publicaciones sobre el Peinador de la Reina o la torre de la estufa; sin embargo, únicamente citaremos a los autores que han realizado las aportaciones más relevantes: Villalón, 1898: 170. Pacheco, 1956:43. Palomino, 1988: 35. Ceán, 1965: 110/131. Gómez Moreno, 1912: 20. Torres Balbás, 1931: 201. López, 2000: 107, Dacos, 2007: 102.

${ }^{4}$ Agapito, 1914: 18.

5 Gómez, 1912: 22.

${ }^{6}$ Nóminas de agosto 1537, Archivo del Patronato de la Alhambra y el Generalife (APAG), Capitanía General del Reino de Granada y Alcaldía de la Alhambra, Caja 1, legajo 22, fol.9 v.

7 Ceán, 1965: 131.

8 Arsenio Mendoza recoge la propuesta de Camón Aznar quien indica que después de Valladolid Julio y Alexandre marcharon a Guadalajara para decorar el Palacio del Infantado (Moreno, 2002: 87). Seguidamente indica que es posible que pasaran por Úbeda (Moreno, 2002: 89). Por otra parte, los dibujos del Cuaderno de Berruguete firmados por Julio Aquiles, se ubican cronológicamente entre 1533 y 1536, es decir entre el final de la decoración del Palacio de Úbeda y la llegada a Granada, manifestando de nuevo la importancia de su estancia en Valladolid. Heredia, 2005: 140.

9 Rosa López Torrijos dató la llegada de Alexandre Mayner y, por tanto, el inicio de la decoración de las estancias imperiales de la Alhambra, en 1535 (López, 1986:42). Para ello, se basó en la demanda presentada por María Alonso, el 16 de octubre de 1545 a Luis Cevallos (defensor de los bienes de Alexandre Mayner, "difundo") donde indica que trabajó 10 años al servicio del pintor. Sin embargo, hemos hallado un documento en el que "Juana Luzón mujer que fue de Alexandre Mayner difunto" reclama los bienes entregados al matrimonio el 5 de noviembre de 1544 . Por consiguiente, si María Alonso había trabajado para Alexandre durante 10 años, el pintor en 1534 ya estaba asentado en Granada (Petición de Juana Luzón, mujer de Alexandre, sobre los bienes y alhajas que había llevado al matrimonio. 5 noviembre de 1544. APAG, L-103-4).

10 Gómez, 1912: 33.

11 Gómez, 1912: 31.

12 Martínez, 2018: 65.

13 Moreno, 2002: 89.

14 Ruiz, 1992: 83-96.
} 
Ramón Martínez Elvira ${ }^{15}$, entre otros historiadores, que nos permiten conocer su entorno familiar y los trabajos realizados en Úbeda y en otras localidades jienenses hasta su fallecimiento en 1556.

De esta forma, constatamos que Julio Aquiles fue un pintor italiano que desarrolló una brillante carrera en España, donde llegó junto con Alexandre Mayner para decorar los palacios imperiales ${ }^{16}$ de Valladolid y Granada, y que acabó convirtiéndose en uno de los artistas más influyentes de la primera mitad del siglo XVI.

El análisis de las fuentes citadas muestra, también, el desconocimiento que todavía subsiste sobre su vida y trayectoria en Italia: ¿quién era Julio Aquiles? ¿dónde y con quien se formó? ¿cómo conoció a Alexandre Mayner? o ¿qué obras le valieron la fama para convertirse en el pintor de las Casas Reales?.

La reconstrucción de la etapa italiana de Julio Aquiles resulta una ardua tarea debido a la escasez de documentación y de obras conservadas.

Según Rosa López Torrijos, Sánchez Cantón fue el primero en relacionar a Julio Aquiles con Julio Aquili, y argumenta que era nieto, y no hijo, de Antoniazzo Romano ${ }^{17}$. Una vinculación familiar que ha sido plenamente aceptada por los historiadores, tanto españoles como italianos, pero que no ha sido analizada.

En este punto, una reciente estancia en Italia, nos ha permitido profundizar en las fuentes documentales del entorno familiar. Para ello, hemos seguido la estela de Angelo Sacchetti-Sasseti, el historiador reatino que ha realizado los mayores aportes documentales sobre Marchantonio (padre de Julio) y de Anna Cavallaro, especialista en Antoniazzo Romano ${ }^{18}$. De esta forma hemos corroborado, analizado y actualizado los documentos existentes en distintos archivos de Rieti y de Roma para reconstruir la vida Julio Aquiles desde su infancia en Rieti hasta su consolidación como maestro tras su paso por el taller de Giovanni da Udine.

El otro gran escollo en nuestra investigación es la escasez de obras conservadas tanto en España como en Italia. Por ello, las pinturas del Peinador de la Reina o de la Estufa de la Alhambra son una fuente tan valiosa. Desde las primeras descripciones, los historiadores, viajeros e investigadores que se han acercado a ellas se han percatado de la extraordinaria relación entre sus bellos grutescos y las decoraciones realizadas por Rafael y Giovanni da Udine en Roma. Estas conexiones estilísticas han conducido a la afirmación unánime de que Julio y Alexandre fueron discípulos de Giovanni da Udine. Por otra parte, Nicole Dacos, apuntó cierto paralelismo con la pintura de Perino del Vaga y la decoración del Palacio del Príncipe en Génova ${ }^{19}$, intervención que se convertiría en el eslabón entre su carrera italiana y su traslado a España.

Hasta el momento, no se ha encontrado ningún documento que certifique la presencia de Julio de Aquiles en los talleres de Giovanni da Udine ${ }^{20} \mathrm{y}$ de Perino del Vaga. Por ello, para profundizar en esta cuestión, hemos conocido y analizado in situ algunos de los espacios donde Julio Aquiles pudo intervenir en Roma (especialmente en las estancias papales de Castel Sant'Angelo) y en Génova.

Como resultado, tras el análisis estilístico de las obras y la revisión de las fuentes documentales y bibliográficas, existentes tanto en España como en Italia, podemos aproximarnos a la trayectoria italiana de Julio Aquiles, protagonista en la introducción de la pintura mural del Renacimiento en España.

\footnotetext{
15 Martínez, 1998: 22-23.

16 Redondo, 2013: 229-248.

17 López, 1986: 43.

18 Angelo Sacchetti publicó la mayoría de los documentos en 1912. Desde entonces, especialistas en la escuela de Antoniazzo Romano como Anna Cavallaro, Gregory Herder o Giovanni Russo han utilizado esta documentación como soporte de sus investigaciones. Nuestra aportación consiste en la actualización de las referencias de los documentos relativos a la vida de Julio Aquiles tras la consulta directa de los fondos del Archivio di Stato da Rieti. Como resultado, en el texto utilizaremos las referencias actuales.

19 Dacos, 2007: 99-101.

20 A nuestro juicio, porque al formar parte del grupo de colaboradores menores no recibió la atención de Vasari. También, hay que tener en cuenta la pérdida de libros de cuentas de los lugares en los que pudo intervenir.
} 


\section{EI entorno familiar de Julio Aquiles en Rieti}

Julio Aquiles perteneció a una importante familia de artistas activos en Roma entre la segunda mitad del Quattrocento y la primera del Cinquecento. Su padre, fue Marcantonio Aquiles ${ }^{21}$, pintor que desarrolló gran parte de su carrera artística en Roma en el taller de su padre Antoniazzo Romano y Diana, hija de la segunda mujer de Antoniazzo ${ }^{22}$.

La cuestión inicial es esclarecer es la fecha de nacimiento y su lugar de origen. La primera referencia que hemos hallado sobre Julio en los archivos italianos se encuentra en un documento del Archivo de Estado de Rieti de 1524. En él se solicita a los hijos de Marcantonio Aquili, Felice y Julio, la finalización de la capilla de Santa Bárbara de la Catedral de Rieti ${ }^{23}$, pero ofrece ninguna información sobre la edad de sus herederos. Por consiguiente, el documento fundamental para identificar su nacimiento es el contrato de Julio para trabajar en la Capilla de Santa María de los Valles de Rieti en $1528^{24}$. Para obtener la carta gremial y trabajar como maestros, los pintores debían de ser mayores de edad ${ }^{25}$. Por tanto, cuando Julio fue contratado debía ser mayor de 25 años.

Por otra parte, Manuel Gómez Moreno y otros historiadores ${ }^{26}$ ya advirtieron que el gentilicio "romano" utilizado por Julio en algunas ocasiones indica su origen. Como veremos a continuación, Marcantonio y su familia se trasladaron de Roma a Rieti a finales de 1505. Como resultado Julio Aquiles debió nacer en Roma antes de esa fecha.

El taller de Antoniazzo Romano era uno de los más prolíficos de la urbe. Este volumen de trabajo permitió a Marcantonio desarrollar su carrera artística tanto en Roma como en otras localidades vecinas. Por ello, no resulta extraño su disponibilidad para ir a Rieti, una de las ciudades más importantes de la Sabina.

En abril de 1505 Antoniazzo aceptó la realización de un estandarte y otros trabajos para las Confraternidades de San Antonio y de Santa María de Rieti. Proyectos que, por lo avanzado de su edad, fueron ejecutados por Marcoantonio siguiendo sus diseños.

De esta forma, tras la marcha de Antoniazzo el 4 de diciembre de 1505, Marcantonio heredó los beneficios estipulados en el contrato de su padre: 100 ducados, 2 cuartos de grano y una casa de alquiler donde poder $\operatorname{trabajar}^{27}$ y vivir con su familia.

Los trabajos de Marcantonio, tuvieron una gran aceptación. En el mes de enero del año siguiente, Marcantonio aceptó el encargo de la confraternidad de San Vicente.Sin embargo, ante la culminación de las obras encargadas a su padre en el mes de marzo, tuvieron que rescindir el contrato de mutuo acuerdo 28 .

Paralelamente, entre 1506 y 1508 realizó el Tríptico de la Resurrección, comisionado por la Confraternidad de San Pedro Mártir, que hoy se encuentra en la iglesia de Santo Domingo de Narni.

Junto a los trabajos para las confraternidades, Marcantonio comenzó trabajar para la catedral. En 1510 inició la decoración mural de la fachada de la torre con el Milagro de la Campana ${ }^{29}$. La pintura se inserta como un cuadro a los pies de la torre. En ella se representa el milagro que se produjo en 1469 cuando la campana medieval de Santa Bárbara se cayó del campanario sin romperse ni herir a nadie ${ }^{30}$.

21 López, 1986: 43.

22 Russo, 2014: 88.

23 Actas del notario Davide Mattei, Archivio di Stato da Rieti (ASRi) 15, 348 (1524) c. 455.

24 Actas del notario Valerio Sonanti, ASRi, 8, 593 (1528).

25 Martínez, 2013: 216.

${ }^{26}$ El primer autor que lo denominó Julio Romano fue el historiador francés Juan Francisco Peyron tras su viaje a España en 1772-1773. Mercadal, 1972: 781.

27 Russo, 2014: 81.

28 Russo, 2014: 81.

29 Russo, 2014: 81.

30 Sacchetti, 1916: 91. 
En la composición se aprecia el momento en el que se rompe el asa de la enorme campana y sale despedida del contrapeso. Afortunadamente, Santa Bárbara interviene sujetando la campana por el centro y la Virgen por el labio, mientras el Niño la "bendice". La escena se desarrolla delante de un acueducto (que correspondería con el acueducto Marcio o con el que canalizaba las aguas del rio Velino) cuyos alargados arcos dejan ver el azul del cielo.

Para su realización, Marcantonio se sirvió de los cartones de su padre y posiblemente contaría con la colaboración sus hijos, Julio y Felice, para la realización de las tareas mecánicas como la molienda de colores o la preparación del revoco. Como resultado, podemos ver las similitudes del rostro de la Virgen de la Campana y de Santa Bárbara con la Virgen y la Magdalena de la Capilla del Rosario, aunque para adaptarse al espacio, los cuerpos de las santas se alargaron dando lugar a dos figuras simétricas. A pesar del gran deterioro que presenta la pintura, aún es posible apreciar la dulzura en el rostro de María, vestida con un manto azul sobre túnica roja y del Niño desnudo sobre el brazo de su madre. Santa Bárbara se representa vestida de rojo con una túnica dorada y azul, sujetando la Torre sobre la mano izquierda. Con todo, se aprecia que el tratamiento de las manos y los rostros es mucho más sutil y delicado en las pinturas del interior de la catedral.

A partir del año siguiente, Marcantonio continuó demostrando su pericia como pintor sobre tabla como se aprecia en El Tríptico de la Resurrección (1511) y la Adoración de los Pastores.

Mientras que la firma en el Tríptico de la Resurrección aleja toda duda sobre su autoría y datación, la tabla de la Adoración de los Pastores, expuesta en el Museo Cívico de Rieti ${ }^{31}$, ofrece numerosas dudas.

La tabla representa la escena de la Adoración de los pastores dentro de una cueva sobre la que se posan unos ángeles músicos con una cartela. Al fondo, un paisaje de colinas ocupado por pastores y un grupo de personajes a caballo que podrían identificados como los Reyes Magos y en la lejanía se distingue una ciudad fortificada y un recinto monástico. Sobre el conjunto se encuentra una luneta donde se ve al Padre Eterno rodeado por querubines dispuestos sobre media mandorla (fig. 1).

Entre las propuestas de autoría, Sacchetti y Herder proponen a Giulio Aquiles como el "Maestro de la Adoración" 32 . Esta idea podría resultar muy sugerente puesto que nos encontraríamos ante la primera obra del artista. Sin embargo, analizando la obra se aprecia cierto carácter retardatario que se aproxima a la tabla del Tríptico de la Resurrección; además por estilo y resolución técnica, la obra no puede ser atribuida a Julio, sino a Marcantonio Romano quien posiblemente estuvo asistido por el joven.

Para corroborar la autoría de Marcantonio, nos resulta fundamental mencionar el documento del Archivo de Estado de Rieti donde se manifiesta que la familia ocupó la casa en alquiler del pretor Bartolomeo Roselli en la calle San Francesco ${ }^{33}$ hasta octubre de 1514. En esta calle se encuentra la iglesia de San Francesco, cuya capilla de San Antonio acogía originariamente la tabla. Como hemos indicado en 1506, Marcantonio había trabajado para esta confraternidad por lo que, a nuestro juicio, siguiendo un contrato similar, en torno a 1512 el artista se encargaría de ejecutar la tabla de la Adoración junto a otros trabajos a cambio de cierta cantidad de dinero, un porcentaje en grano y otro en ayuda para el alquiler hasta el final de la obra, es decir hasta octubre de 1514, fecha de liquidación del contrato de la vivienda. Seguidamente, Marcantonio compró una casa con huerto en Porta Cinthya ${ }^{34}$ junto a la catedral de Rieti.

De esta forma, se evidencia el alto poder adquisitivo de la familia y la consolidación de la carrera artística de Marcantonio Romano, junto al que Julio tuvo la oportunidad de aprender el arte de la pintura en los distintos soportes en los que posteriormente demostró notables cualidades artísticas.

\footnotetext{
31 AA.VV., 2001: 37.

32 Sacchetti, 1916: 7. Herder, 1980: 149.

33 Actas del notario Girolamo Meloni, ASRi, 2, 406 (1511-1514) c. 604.

${ }^{34}$ Actas del notario ANDR, Marino Clarelli, ASRi, 2, 494 (1516-1517) c. 68.
} 


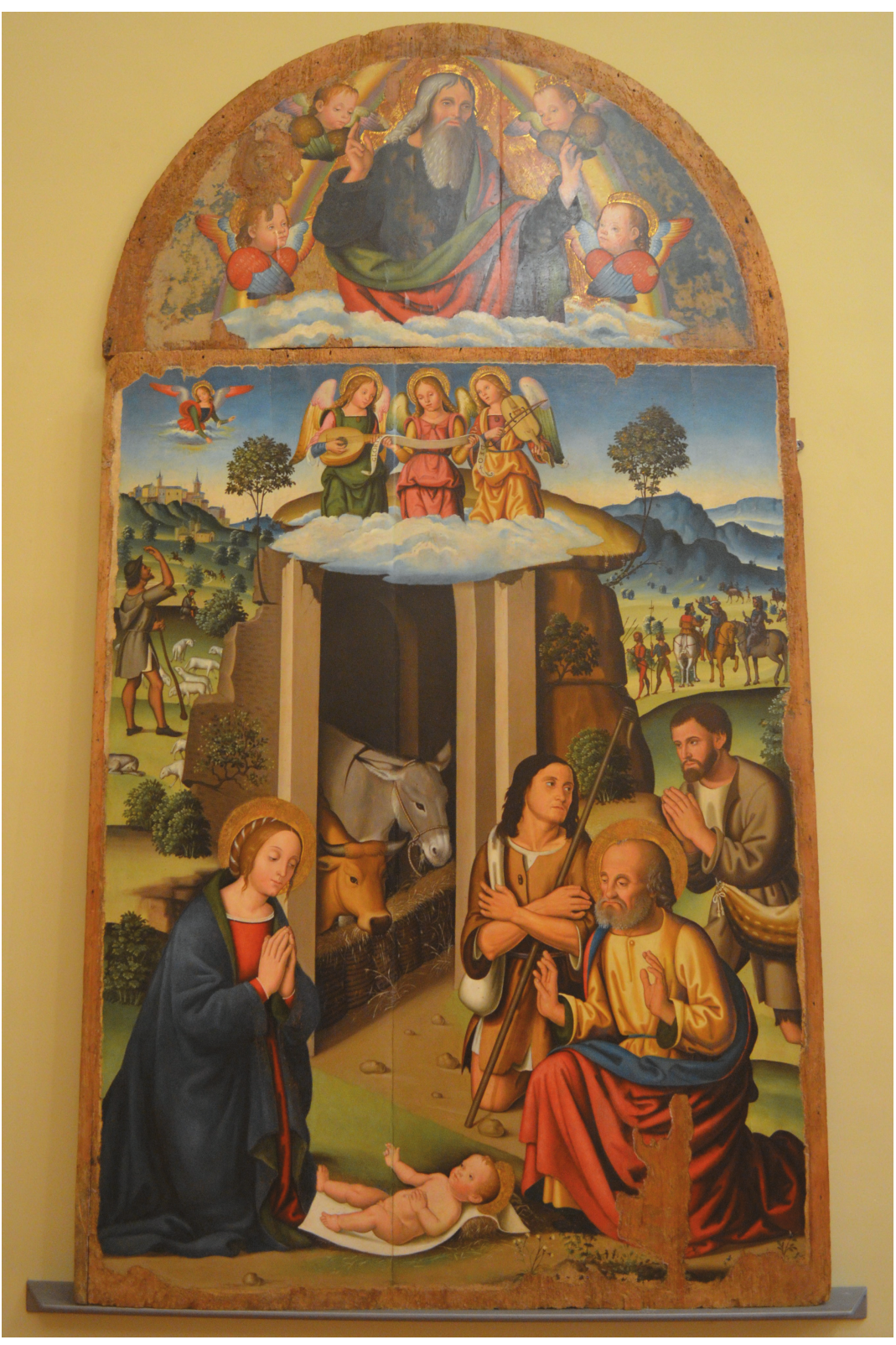

Fig. 1. Marcantonio Aquili. Adoración de los Pastores. Siglo. XVI. Tempera sobre tabla; tabla $157 \mathrm{x}$ $120 \mathrm{~cm}$, luneta $64 \times 121$. Procedente de la Capilla de San Antonio en la Iglesia de San Francesco. Rieti. Conservada en el Museo Cívico de Rieti (Fotografía de la autora).

\section{La inserción en el círculo de Rafael}

Durante estos años Marcantonio se había convertido en el artista más influyente de Rieti, pero el centro artístico por excelencia era Roma. Por lo que resulta lógico pensar que el artista enviara a su hijo a la capital para que continuara con su formación.

Aunque en enero de 1517 Marcantonio había firmado el contrato para la decoración pictórica de la capilla de Santa Bárbara de la catedral de Rieti ${ }^{35}$, el maestro se encontraba en Roma en julio de ese año ${ }^{36}$. Por otra parte, el requerimiento de los herederos de Dionisos (el mecenas de

35 Actas del notario Davide Mattei, ASRi 9, 342 (1515-1518) c. 22.

36 Russo, 2014: 88. 
la capilla mencionada) en julio de 1518 indica que ésta aún no se había terminado ${ }^{37}$. Entre los motivos que pudieron retrasar la ejecución de la obra, estimamos que se encuentra el traslado de Marcantonio a la capital (donde sus hermanos Bernardino y Evangelista continuaban trabajando en el taller familiar) para favorecer la integración de Julio en los nuevos círculos artísticos.

Precisamente en ese año Rafael había emprendido una de sus empresas más significativas en Roma: la decoración de las logias vaticanas. Para su ejecución, contó con los pintores más relevantes de su círculo: Giulio Romano, Giovanni da Udine, Giovanfrancesco Penni o Perino del Vaga y numerosos artistas foráneos como los españoles Pedro Machuca y Alonso Berruguete, que trabajaron "junto a otros muchos jóvenes artífices ${ }^{38 "}$ ". Entre ellos debió encontrarse el joven Julio Aquiles.

El primero en relacionar la paleta de Julio Aquiles con la pintura italiana de los maestros del Renacimiento fue Pacheco en el Arte de la pintura cuando indicó que de Roma: "pienso yo que se enriquecieron Julio y Alexandre, si ya no es que fuesen discípulos de Juan de Udine, o de Rafael de Urbino ${ }^{39}$ ". Por su parte, Antonio Palomino escribió en su tratado que durante su estancia en Granada de 1712 "encontró unos papeles curiosos de estos dos ínclitos varones Julio y Alexandre, pintores eminentes (...) que se presupone con gran fundamento, fueron italianos (...) porque aprendieron el arte de la pintura en Roma, en la escuela de Juan de Udine, discípulo de Rafael ${ }^{40}$ ".

Aunque no se trate de una fuente muy sólida (porque no conocemos su formación artística), la fuerte impronta del maestro de Urbino, fue también detectada por Samuel Edward Cook. Tras su paso por Granada en 1829-1832, el viajero declaró que, a pesar de su deterioro, las pinturas del Tocador de la Reina son "lo más cercano a los frescos de Rafael que yo haya visto tanto fuera como dentro de Italia" (...) "el colorido es casi tan bueno y el estilo muy similar siendo la única diferencia la falta de relieve y de redondeces ${ }^{41}$ ".

Desde el punto de vista científico las principales aportaciones sobre la repercusión de la escuela de Rafael en la paleta Julio Aquiles han sido ofrecidas por Manuel Gómez Moreno y, posteriormente por Rosa López Torrijos y Nicole Dacos.

Aunque Gómez Moreno había abordado las relaciones entre los grutescos de la Alhambra y los ejecutados por Udine en Roma, Rosa López Torrijos continuó profundizando en los grutescos, así como la influencia de Udine en el naturalismo de las Salas de las Frutas. Concretamente en su artículo sobre la "Escuela de Rafael y el bodegón español", tras analizar los racimos de flores y frutas del alfarje de las Salas de las Frutas de la Alhambra, apuntó que su antecedente directo se encuentra en los ramos diseñados por Rafael y realizados por Giovanni da Udine en las logias vaticanas: "Todo esto hace suponer, una vez más, que los pintores de la Alhambra conocían de cerca lo hecho por Rafael y Udine, y que, no sólo lo conocían, sino que lo habían copiado, estudiado y asimilado, lo que probablemente indica su colaboración directa en las obras romanas ${ }^{42}$ " (fig. 2).

Al igual que en las logias, los ramos de las Salas de las Frutas de la Alhambra se componen por hojas, flores y frutos, pero en forma independiente. De hecho, es posible identificar los distintos frutos que formaban parte de los jardines de la Alhambra ${ }^{43}$, cuyos volúmenes se consiguen a través de la modulación de la luz sobre el fondo neutro frío (fig. 3). Para conseguir este efecto, los frutos debieron ser copiados del natural, o "al vivo" técnica que según Vasari, utilizó Giovanni da Udine para realizar las composiciones naturalistas de la Villa Farnesina ${ }^{44}$.

Por otra parte, Nicole Dacos ${ }^{45}$ y María del Carmen Heredia ${ }^{46}$ han ampliado las fuentes para el conocimiento de la obra de Aquiles al identificar su mano entre los dibujos de grutescos del

\footnotetext{
37 Actas del notario Camilo Carotti, ASRi, 3, 390 (1517-1518) c. 181.

38 Campos, 2013: 46.

39 Pacheco, 1956: 43.

40 Palomino, 1988: 35.

41 Viñez, 2007: 168.

42 López, 1986: 46.

43 Ramón-Laca, 1999: 52

44 Vasari, 2012: 1107.

45 Dacos, 1997: 24-33.

46 Heredia, 2005: 132-144.
} 

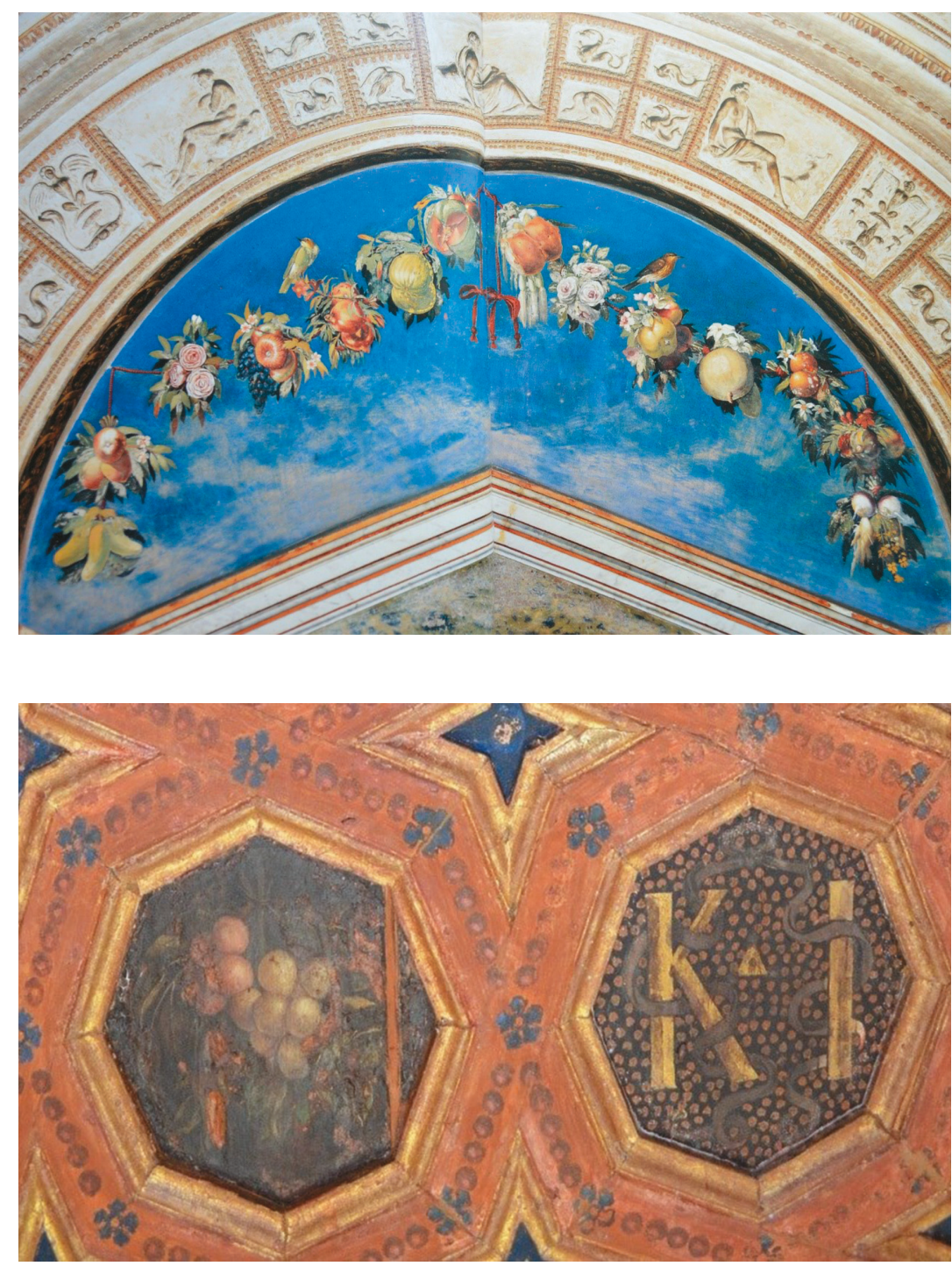

Fig. 2. Detalle de la decoración con ramos de frutas de las Logias vaticanas. Roma (Fotografía. Dacos, Nicole (2008): Las logias del Vaticano. Roma. Lunwerg).
Fig. 3. Octógonos con Ramo de ciruelas e Iniciales $K$ (arolus)I. Salas de las Frutas. Alhambra, Granada. (Fotografía de la autora).

museo Metropolitano de Nueva York, el Museo del Louvre de París y en el Libro de bocetos de Alonso Berruguete de la Fundación Lázaro Galdiano de Madrid.

Tras el minucioso análisis de los dibujos podemos afirmar la indudable conexión de los grutescos de las logias vaticanas con los bocetos del palacio de Cobos en Valladolid y en las pinturas de la Casa Real de Granada, ciudades en las que colaboró con Alonso Berruguete y Pedro Machuca, respectivamente, antiguos integrantes del círculo de Rafael en Roma.

Pensamos que la utilización de tal variedad de modelos procedentes de las logias en la decoración de grutescos y elementos naturalistas sólo pudo producirse a través del conocimiento directo de las decoraciones romanas. Por tanto, aunque resulte extremadamente complejo identificar la paleta del joven entre las pinceladas de los grandes pintores, la inserción de Julio Aquiles en el taller del maestro de Urbino debió de producirse en aquel momento.

Por su juventud Julio se encargaría de labores menores y secundarios en el grupo de colaboradores de Giovanni da Udine, como era usual. Así inició su especialización como decorador. De esta forma, el joven adquirió una sólida formación en el campo de la pintura mural, desde el punto de vista técnico e iconográfico; tomando del discípulo del Rafael gran parte de los modelos naturalistas, anatómicos y compositivos que utilizó años más tarde. 
Además, como hemos visto, Aquiles se benefició de la compleja red de relaciones de amistad del taller de Rafael; algo que marcará el rumbo de su carrera en Italia y que décadas más tarde lo conducirán a España.

\section{Julio Aquiles, discípulo de Giovanni da Udine}

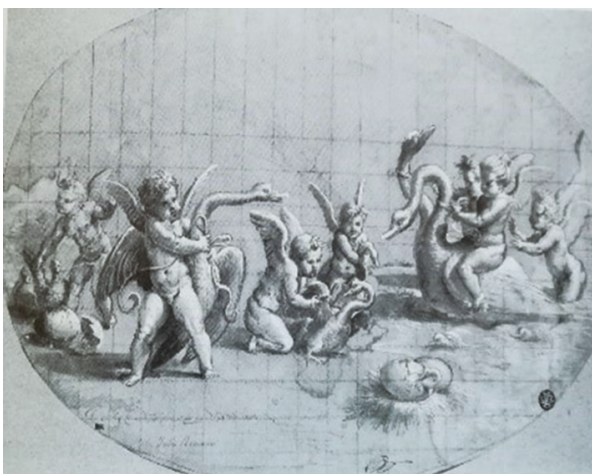

Fig. 4. Giulio Romano. Juego de putti, dibujo. Museo del Louvre, gabinete de Dibujos, París (Fotografía: Rèunión des Musèes Nationaux, París).
Durante estos años Julio habría demostrado sus cualidades artísticas y su proyección en el mundo de la pintura en Roma donde estaba afincado ${ }^{47}$. No obstante, el afianzamiento de Aquiles en el taller de Giovanni da Udine debió de producirse tras la muerte de Rafael, en abril de 1520.

Una de las primeras intervenciones de Aquiles en el círculo de Udine podría hallarse en Villa Madama, encargada por Julio de Médici (futuro Clemente VII) a Rafael y que, tras su muerte, fue concluida por Giovanni da Udine y Giulio Romano.

Para argumentar la intervención de Julio Aquiles en esta empresa, Nicole Dacos distingue su mano en algunas de las decoraciones de las bóvedas y le atribuye directamente algunos los grabados utilizados para los cartones ${ }^{48}$. Aunque coincidimos en algunas de las atribuciones, diferimos con la investigadora en la autoría de Julio Aquiles del grabado del Juego de Putis conservado en el Gabinete de dibujos del Museo del Louvre de Paris. Según Dacos, este cartón sirvió a Julio Aquiles tanto en Italia como en España y la grafía es muy similar a la de los dibujos de Nueva York ${ }^{49}$. Sin embargo, después de analizar estos dibujos, discrepamos de la atribución de la historiadora. En primer lugar, porque el nombre "Julio" de los dibujos del Museo Metropolitano de Nueva York forma parte de las anotaciones de Andrés Melgar, por lo que, hasta el momento, no conocemos la firma de Aquiles. Además, la calidad técnica del cartón de los Amorcitos es muy superior a la de las composiciones hechas por Julio en Valladolid años más tarde. De esta forma, corroboramos la afirmación más extendida entre los historiadores: el grabado de Villa Madama fue realizado por Giulio Pippi, más conocido como Giulio Romano (fig. 4).

El hecho de que Aquiles no realizara el cartón, no impide que el joven interviniera en la decoración de Villa Madama formándose como muralista y tomando modelos que posteriormente le servirán para la decoración de otros espacios. En efecto podemos corroborar su influencia en el ornato de otros lugares en lo que intervino Aquiles, como la estufa de Clemente VII o en las habitaciones nuevas de la Alhambra, donde trazó grutescos y formas geométricas hechas con guirnaldas y salpicadas por delicadas figuras de animales, la incorporación de cuadros con escenas mitológicas sobre las hornacinas, en la representación de los amorcillos, etc.

Con el inicio del pontificado de Clemente VII, Giovanni da Udine comenzó a encabezar los principales proyectos de la urbe: desde el diseño de los estandartes y los arcos triunfales, hasta la remodelación de las estancias pontificias. Para ello, contó con sus colaboradores habituales, entre los que se encontraban Domenico Rieti "Zaga" y Julio Aquiles, e incorporó otros $\operatorname{artistas}^{50}$ para la ejecución de proyectos puntuales. En el Libro de Cuentas de Giovanni da Udi-

47 En marzo de 1520 se produjo el traslado de la hipoteca de la parte correspondiente a la dote de Diana (Russo, 2014: 88.) De este documento se desprende que ésta podría ser reformada para convertirse en la residencia de sus herederos. Puesto que no tenemos constancia de que Felice desarrollara una carrera artística o residiera fuera de Rieti, pensamos que Julio se estableció en la casa familiar-integrada en el taller de Antoniazzo Romano en Roma.

48 Dacos, 2000: 113

49 Dacos, 2000: 113.

50 Dacos, 2000: 111. 


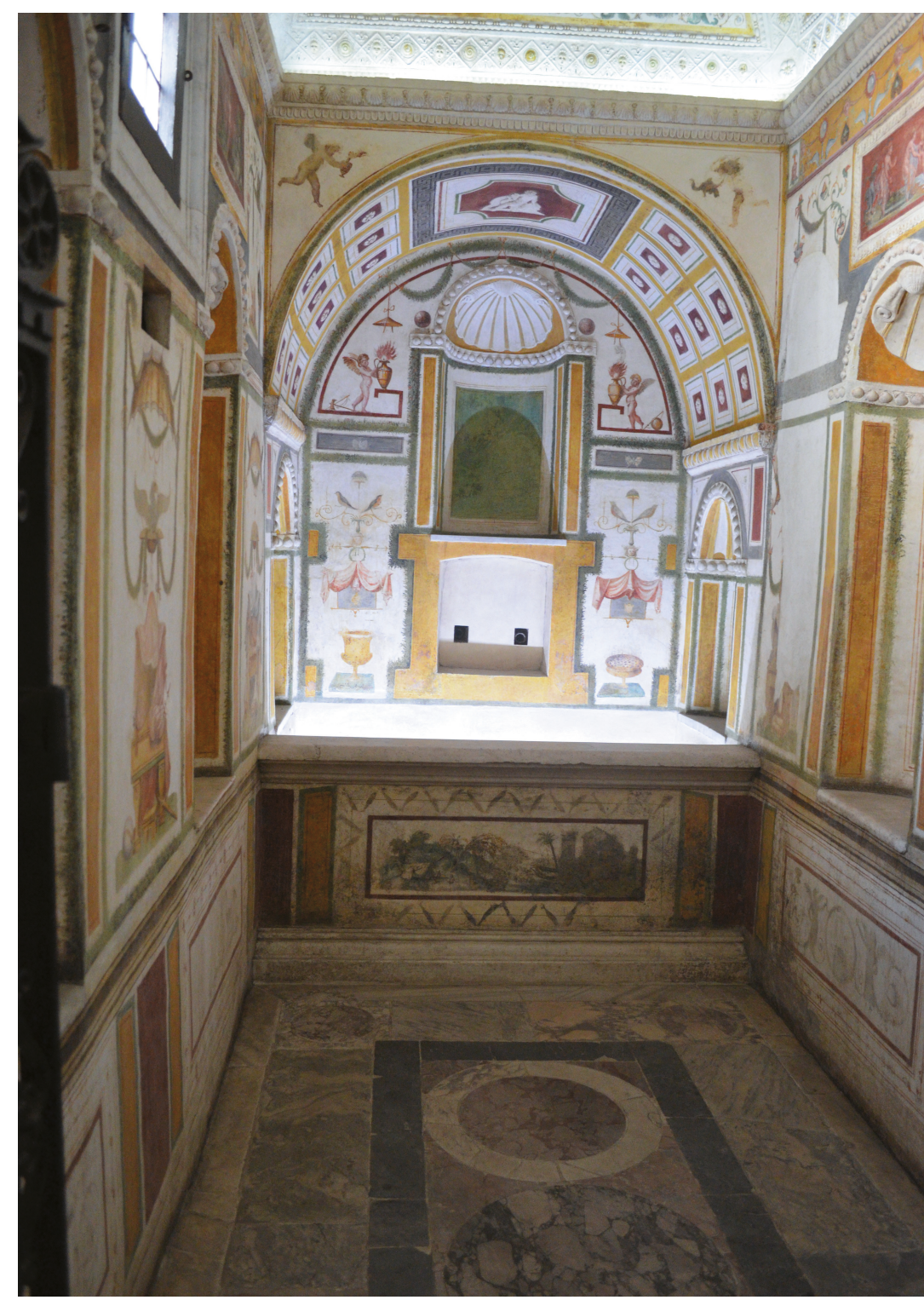

Fig. 5. Giovanni da Udine y colaboradores (Julio Aquiles, Domenico Zaga y Alexandre Mayner). Stufetta de Clemente VII. Castel Sant'Angelo, Roma. (Fotografía de la autora).

ne destaca la presencia de Alessander, un artista que colaboró en la elaboración de estandartes entre 1524 y $1526^{51}$. A pesar del enorme vacío documental existente en la biografía de Alexandre Mayner, su figura ha estado indisolublemente unida a Julio y ambos aparecen como seguidores de Giovanni da Udine. En este contexto, a nuestro juicio, estos pagos confirman la integración de Alexandre Mayner en el entorno de Udine, donde Julio ya era un importante colaborador.

La intervención más significativa de Julio Aquiles en Roma fue la participación en la decoración pictórica de la estufa de Clemente VII en Castel Sant'Angelo entre 1525 y $1527^{52}$.

El estudio de esta estufa es un tema controvertido por la ausencia de documentación y de crónicas respecto a su construcción y decoración. Con todo su conocimiento in situ nos ha permitido realizar un minucioso análisis de su técnica y programa iconográfico.

51 Udine, 1987: 163-165.

52 Dacos, 2000: 111. 
La primera referencia la ofrece Vasari cuando indica que "Hizo Giovanni da Udine en Castel

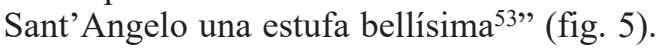

La estufa se encuentra entre los aposentos papales y el patio del Pozo. Concretamente, se ubica en una entreplanta, por lo que hay que subir dos tramos de escaleras decorados por pinturas que imitan tapices y damascos, sobre las que se distinguen los símbolos de los Médici.

Tras cruzar el portal de mármol blanco con las iniciales de Clemente VII, se encuentra una habitación pequeña de 3.45 por 1.48 metros ${ }^{54}$ cuadrados, caracterizada por la existencia de una bañera.

En la parte superior de la estancia hay una bóveda de espejo enmarcada por molduras de estuco con conchas y diamantes, en los que se insertan rosetas y máscaras angelicales intercaladas por flores de lis. La parte central se divide en tres cuadrados donde están los escudos de los Médici. El salmer se decora con grutescos y guirnaldas entre las que hay medallones octogonales con puttis cabalgando sobre delfines y otros animales marinos realizados en estuco blanco sobre fondo oscuro.

A modo de reflejo encontramos la solería de mármoles coloreados que conforman distintas formas geométricas.

En las paredes se desarrolla un extraordinario programa iconográfico sobre fondo blanco caracterizado por la existencia de grutescos, festones y guirnaldas con roleos sobre leones y esfinges o trofeos dorados. Los muros se subdividen en cuatro zonas separadas por las hornacinas y definidas por gruesas líneas azules.

Más allá de la riqueza ornamental que inunda todo el espacio, las pinturas más significativas son las escenas mitológicas (que igual que en Villa Madama se encuentran sobre las hornacinas) y la representación de los tronos de los dioses.

Aunque resulta difícil interpretar las escenas como un programa completo, el ciclo de historias parece estar dedicado al amor. Por ello, identificamos a Psique consiguiendo el frasco de la belleza Eterna ${ }^{55}$; a Cupido y Diana (aludiendo posiblemente al mito de Niobe ${ }^{56}$ ); la traición a Vulcano y una escena de Venus y Cupido (fig. 6).

Junto a las historias mitológicas destacan los tronos de los dioses representados en los paneles laterales de las hornacinas. La característica más significativa, es que los tronos aparecen vacíos, ocupados únicamente por los atributos de los dioses como si se hubiesen despojado de sus vestiduras antes de darse un baño. Sobre ellos, se encuentra "una sombrilla" que remite directamente a las utilizadas en la Domus Aurea y una especie de capelo invertido.

Entre los dioses identificamos a Mercurio por el caduceo y el casco alado, y a Júpiter, representado por la espada, el globo y un águila con las alas extendidas. La lira y las flechas identifican el lugar de Apolo, bajo una cesta llena de manzanas de oro. También distinguimos unas sandalias sobre un taburete, y una hoja de palma, por lo que podría ser el lugar de Venus o Neptuno ${ }^{57}$ y finalmente atisbamos un casco, un escudo y una gallina, seguramente la ubicación de Minerva.

Al fondo de la habitación se encuentra la bañera cubierta por una bóveda dorada con casetones con florones y que confluyen en el octógono central donde aparece una figura vertiendo agua. Entorno a la bañera hay tres hornacinas, la pared se decora con amorcitos que portan urnas flameantes; en el cuerpo bajo hay delicadas estructuras que parecen posarse sobre un brasero (que indicaría el grifo del agua caliente) y una gran vasija (referencia al lugar de salida del agua fría ${ }^{58}$ ).

Tras analizar la decoración de la estufa de Clemente VII apreciamos una técnica de ejecución distinta a la utilizada por el maestro de Udine. Una pincelada más suelta, colores opacos y menor movimiento en las composiciones, elementos que corroboran la propuesta de Dacos: Julio Aquiles y Domenico Zaga ${ }^{59}$, entre otros colaboradores, ejecutaron el programa iconográfico diseñado

\footnotetext{
53 Vasari, 2012: 1108.

54 Edwards, 1983: 29.

55 Edwards, 1983: 30.

56 Ovidio, 1995: 199.

57 Edwards, 1983: 30.

58 Todo el conjunto estaría provisto de un sistema hidráulico para facilitar el baño y favorecer la circulación del aire caliente por el interior de la estufa. Edwards, 1983: 31-2.

59 Dacos, 2007: 95.
} 


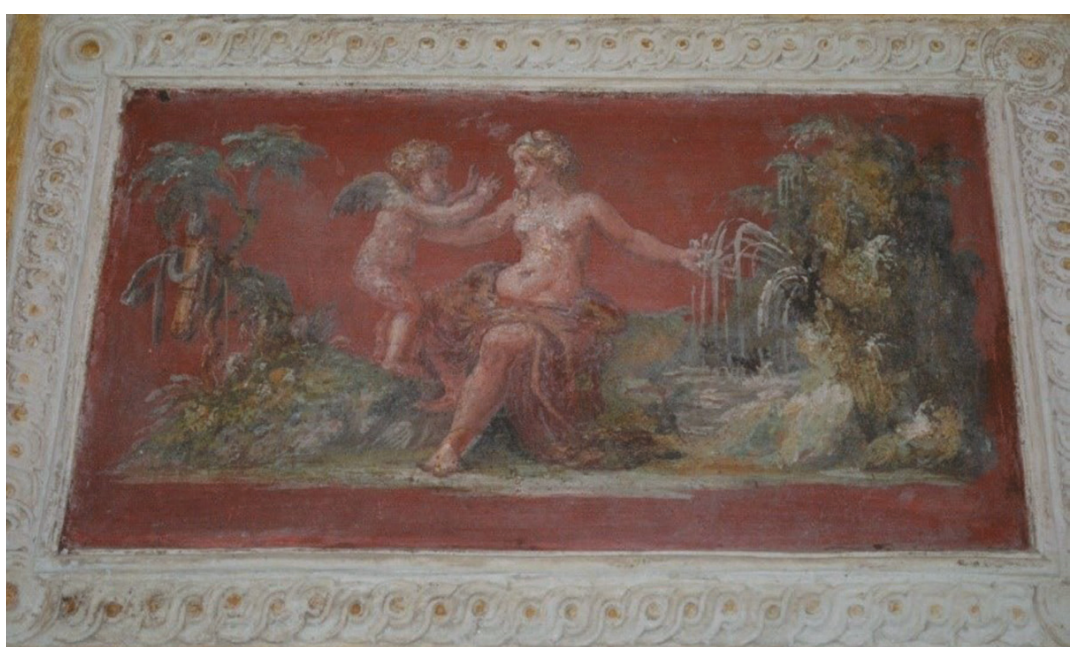

Fig. 6. Giovanni da Udine y colaboradores (Julio Aquiles, Domenico Zaga y Alexandre Mayner) Venus y Cupido. Stufetta de Clemente VII. Castel Sant'Angelo, Roma. Fotografía de la autora).

por Giovanni da Udine para este espacio. De esta forma se explica la similitud de algunas de las composiciones de la estufa de Castel Sant'Angelo y de la estufa de la Alhambra.

\section{El maestro Julio Aquiles en 1528 en Rieti}

La labor de Clemente VII como mecenas y promotor artístico durante los primeros años de su pontificado, contrastan con una desafortunada labor política que dio lugar al Saco de Roma, el 6 de mayo de 1527.

Ante el desastre humano y material que las tropas imperiales causaron en la ciudad, numerosos ciudadanos abandonaron la urbe, incluidos los artistas que se dispersaron retornando en muchos casos a sus ciudades de origen.

En un principio podríamos pensar que, al volver a Rieti ya como maestro, Julio Aquiles retomó los trabajos de Marcantonio. Sin embargo, tras su formación en Roma, el pintor había desarrollado un estilo propio que distaba de los gustos del Cabildo con el cual tuvo problemas desde la muerte de su progenitor.

Como indicamos anteriormente, durante la estancia de Marcantonio en Roma la decoración de la capilla de Santa Bárbara de la catedral de Rieti había sido interrumpida. De hecho, en la petición realizada por los herederos Dionisos, patrono de la capilla, en julio de 1518, se manifiesta que la obra aún estaba inacabada ${ }^{60}$. En $1524^{61}$ los descendientes de Dionisos y los representantes de la catedral reclamaron a los hijos de Marcantonio, Julio y Felice, la culminación de las pinturas o la restitución del dinero recibido. No tenemos constancia de que Felice continuara los pasos de su padre, y como hemos visto, Julio estaría en Roma, por lo que este requerimiento no tuvo ninguna repercusión. Tampoco se consiguió en 1527, cuando se les exigió la conclusión de la obra llamando a un "buen pintor"; si no lo hacían deberían restituir el dinero ${ }^{62}$.

De todo lo argumentado se deduce que Julio tenía cualidades suficientes para realización del trabajo, lo cual contrasta con la petición del Cabildo de llamar a "un buen pintor". Por consiguiente, suponemos que el artista no terminó la obra debido a los problemas personales con los comiten-

${ }^{60}$ Actas del notario, Davide Mattei, ASRi 9, 342 (1515-18) c. 22.

${ }^{61}$ Actas del notario Davide Mattei, ASRi, 15, 348 (1524) c. 455.

62 Actas del notario Davide Mattei, ASRi, 18,351 (1527) c. 195. Este documento, ya publicado por Sacchetti en 1966, conduce al historiador a pensar que Julio, sería el primer candidato a terminar la capilla de Marcantonio tras su regreso de Roma en 1528, sin embargo, pensarían que su calidad distaba de la de su padre por lo que decidieron encargar las obra a los hermanos Torresani. Sacchetti: 1966: 4. 
Fig. 7. Cristo crucificado. Principios del siglo XVI. Madera esculpida y pintada; 175 x $180 \mathrm{~cm}$. Procedente de la Iglesia de S. Lucia, luego en la Iglesia de la Misericordia. Conservada en el Museo Cívico de Rieti. (Fotografía de la autora).

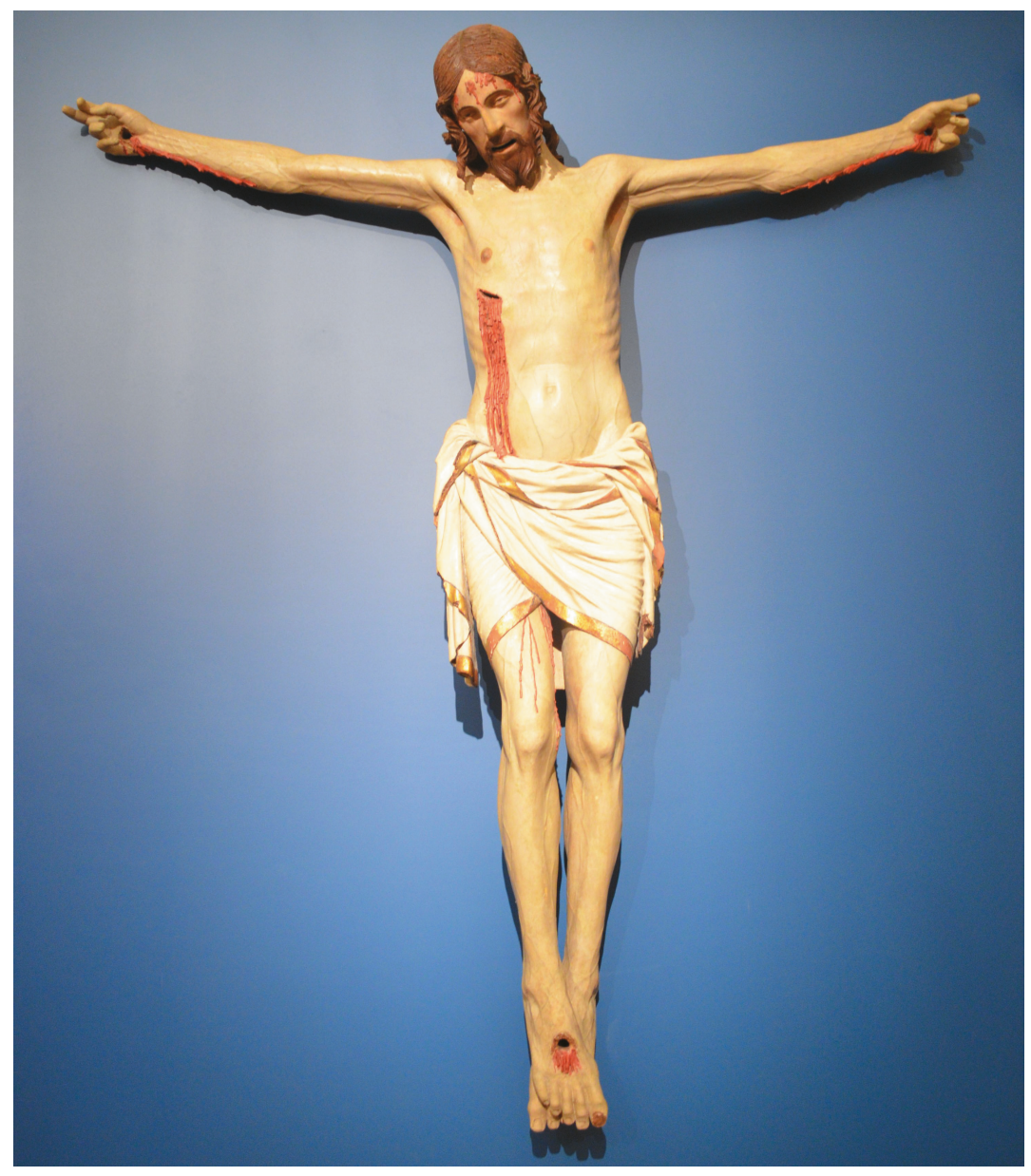

tes, tensión que se agravó con la llegada de Lorenzo y Bartolomeo Torresani, los dos pintores veroneses que finalmente decoraron la capilla de Santa Bárbara de la catedral de Rieti en $1532^{63}$.

Pese a las contrariedades, la pericia de Julio fue admirada en la ciudad. En efecto, en el contrato del 6 de septiembre 1528 firmado con la Confraternidad de Santa Maria dei Valli64se alude al "maestro Julio del maestro Marcantonio romano de Rieti", asociando la ciudad al artista que pertenecía a la notable familia de pintores. El encargo consistía en "la pintura de la capilla de dicha confraternidad y comenzar con las figuras desde arriba y un epitafio y con una dedicatoria y con un friso con figuras y cornisas y pintar y renovar la Cruz del Crucifijo y con azul y oro, decorar dicho crucifijo con corona, cruz y clavos por precio de 25 ducados en total contando 11 por adelantado y comprometiéndose a dar los otros 15 y el resto una vez completado el trabajo ${ }^{65}$ ". Desafortunadamente, la iglesia ha desaparecido por lo que no podemos admirar las pinturas murales, pero sí es posible contemplar el Cristo Crucificado, que en la actualidad se conserva en el Museo Cívico de Rieti ${ }^{66}$ (fig. 7).

${ }^{63}$ Sacchetti, 1966: 4.

64 Actas del notario Valerio Sonanti, ASRi, 8, 593 (1528).

65 Traducción del texto trascrito por Angelo Sacchetti-Sassetti. Antoniazzo Marcantonio e Giulio Aquili a Rieti. Notizie e documenti. Estratto da L'arte di Adolfo Venturi. Anno 19-Fasc II. - Tipografia dell' Unione Editrice. Roma, 1916. Fuente citada por Sacchetti, Arch.Not.rog.di Valerio Sonanti, vol.8, c.487/ Ubicación actual: Actas del notario Valerio Sonanti, ASRi, 593 (1528) c. 487.

${ }^{66}$ La última referencia conocida al respecto la encontramos en la guía de museo más reciente. AA.VV. Guida, 2001: 39 . 
Acabada esta comisión, el desgaste de las relaciones con la Catedral y las posibilidades que se vislumbraban desde otras partes de Italia, motivaron que Julio Aquiles se marchara definitivamente de Rieti en 1528.

\section{Del Palacio del Príncipe a la Casa Real del Emperador}

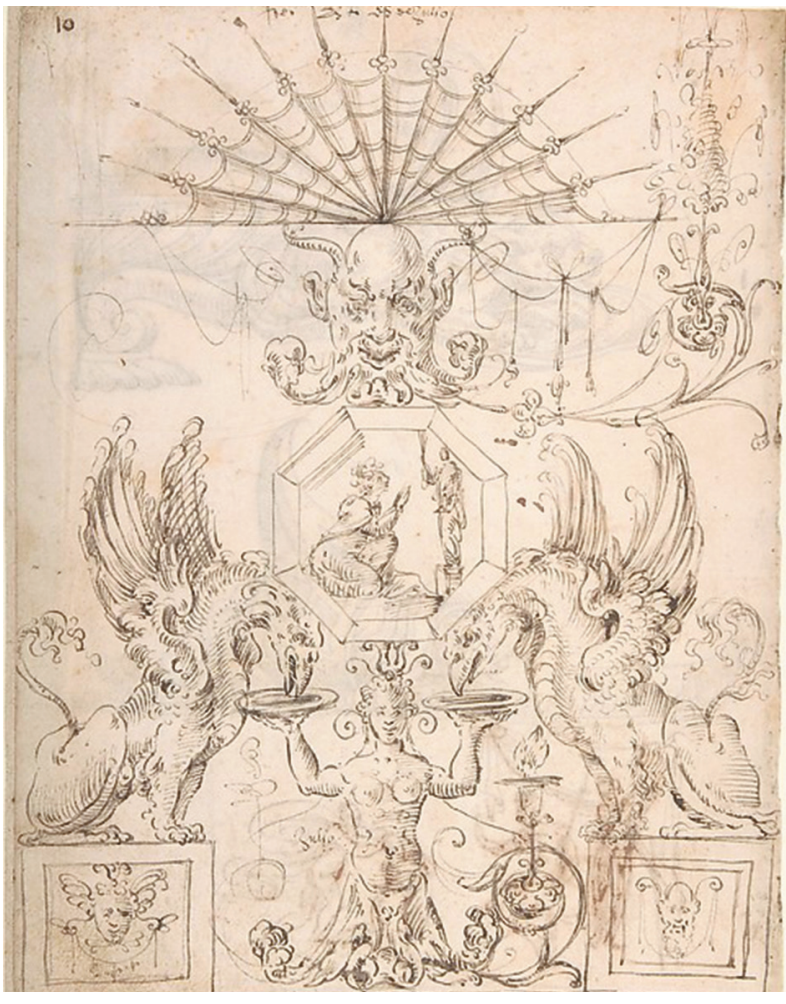

Fig. 8. Diseño de grutesco con un panel octagonal en el centro $y$ dos grifos bebiendo de los platos ayudado por una criatura hibrida (recto). Atribuido a Andrés Melgar, copia de Julio Aquiles.

C.1546-1550. $\mathrm{n}^{\circ}$ clasificación: 52.570.321. Gabinete de dibujos y estampas del Museo Metropolitano de Nueva York.
Como planteó Nicole Dacos lo más probable es que, tras su paso por Rieti, Julio se dirigiera a Génova donde Perino del Vaga (antiguo compañero en el equipo de Giovanni da Udine en las estancias vaticanas) había comenzado a trabajar bajo el mecenazgo de Andrea Doria $^{67}$.

Tal y como indica Vasari, Perino diseñó los modelos y dirigió los trabajos que fueron ejecutados por sus colaboradores ${ }^{68}$.

Los integrantes más conocidos del círculo de Perino en Génova son: Girolamo da Treviso, Giovanni Antonio de' Sacchis "Il Pordenone", Luzio Romano y Domenico Beccafumi. No obstante, paulatinamente, han ido apareciendo los nombres de otros integrantes del equipo como Domenico "Zaga" que, según Nicole Dacos, pintó en la sala del Zodiaco y Julio Aquiles que intervendría en la sala de Perseo $^{69}$.

Después de conocer y analizar in situ las estancias del Palacio del Príncipe pensamos que es posible diferenciar la paleta de Julio Aquiles entre los grutescos de varias salas del palacio. Para ello hemos comparado estilísticamente las pinturas realizadas en Roma, los bocetos del Palacio de Valladolid conser-

vados en el Museo Metropolitano de Nueva York, en el Museo del Louvre y en el Museo Lázaro Galdiano de Madrid, y las pinturas conservadas en la Alhambra y en Úbeda.

Junto a la sala de Perseo, la estancia más significativa es la sala de los Sacrificios. En ella, destacamos las composiciones realizadas sobre fondo rojo en las que se representan tronos de dioses antiguos flanqueados por figuras fantásticas con un musculado cuerpo de león, pico de águila y amplias alas coloreadas, de las que pende una cadena con piedras preciosas. Este esquema, con algunas variaciones, se encuentra entre los bocetos del Museo Metropolitano de Nueva York y en la sala de Faetón en la Alhambra (fig. 8].

Por otra parte, hemos reconocido similitudes entre las composiciones y los paisajes de las historias de Faetón de la estufa de la Alhambra (fig. 9) y las escenas de la sala de Faetón del

\footnotetext{
67 Dacos, 2007: 99-100.

${ }^{68}$ Cecchin, 2001: 20.

69 Dacos, 1997: 29-30. Dacos, 20007: 100.
} 


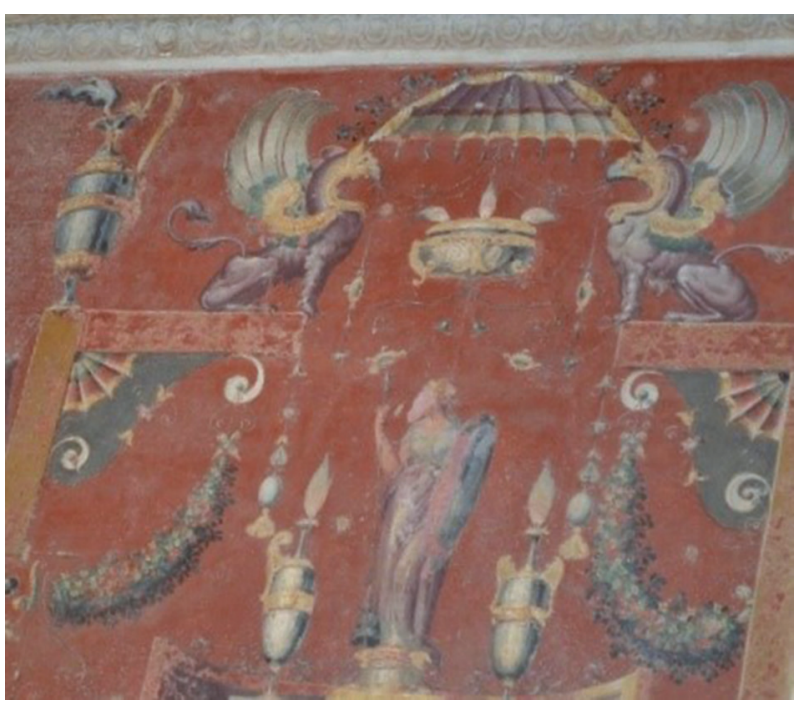

Fig. 9. Julio Aquiles. Grutesco de la Sala de Faetón. Peinador de la Reina. Granada. (Fotografía de la autora).

Palacio del Príncipe de Génova donde también se desarrolla este episodio extraído de la Metamorfosis de Ovidio.

Como indicamos al inicio de este artículo, la decoración de grutescos de la estufa de la Alhambra se atribuye a Julio, mientras que Alexander sería el especialista en la realización de las historias de Faetón y las escenas de la Campaña de Túnez ${ }^{70}$. En este contexto, la relación entre las composiciones de Génova y de Granada, indicarían que Alexandre también formó parte del taller de Perino del Vaga en Génova y, de allí, trajo los diseños para realizar las escenas mitológicas de la Alhambra.

De esta forma se refuerza la hipótesis de que Julio Aquiles y Alexandre Mayner formaron parte del círculo de Perino en Génova. A nuestro juicio, estas intervenciones realizas en el Palacio del Príncipe, conocidas y admiradas por el Emperador y Francisco de los Cobos a su paso por Génova en 1533, fueron las que avalaron a Julio Aquiles y Alexandre Mayner para ser contratados como decoradores del Palacio de Cobos en Valladolid y posteriormente en la Casa Real de la Alhambra en Granada ${ }^{71}$.

\section{BIBLIOGRAFÍA}

AA.VV. (2001): Guida al Museo Civico di Rieti. Sezione storioco-artistica. Roma: Sograf.

Agapito y Revilla, Juan (1914): El arte en Valladolid. Notas sueltas. Valladolid: Establecimiento Tipográfico del Colegio Santiago para huérfanos del arma e caballería.

Agapito y Revilla, Juan (1925-1943): La pintura en Valladolid. Tomo1. Valladolid: Imprenta Castellana.

Blázquez Mateos, Eduardo (1994): "El Peinador de la Reina en La Alhambra. Los paisajes testimoniales de conquistas". En: Cuadernos de arte de la Universidad de Granada, 25, Granada, pp. 11-21.

Campos Pallarés, Liliana (2013): Pedro Machuca en Italia y en España, su presencia y huella en la pintura granadina del quinientos. Tesis doctoral dirigida por el Dr. Antonio Juan Calvo Castellón. Universidad de Granada.

Cavallaro, Anna (2013): Antoniazzo Romano. Pictor Urbis (1435/1440-1508). Roma: Salvana Editoriale.

Cean Bermúdez, Juan Agustín (1965): Diccionario histórico de los más ilustres profesores de las Bellas Artes de España. Vol.6. Madrid: Reales Academias de Bellas Artes de San Fernando y de la Historia.

Cecchin, Giacomo (2001): Sulle orme di Perino. Viaggio intorno ad un artista “moderno". Mantova: Tre Lune Edizioni di Luciano Parenti \& C.sas.

Cruces Blanco, Esther (2000): "La documentación sobre Pedro Machuca en el Archivo de la Alhambra. Organización y procedimentos em las obras reales (1520-1550)". En: Cuadernos de la Alhambra, 36, Granada, pp. 35-50.

Dacos, Nicole (1992): "Lo Zaga a Genova". En: Disegni genovesi dal Cinquecento al Settecento, Giornate di studio..., Firenze, pp. 37-44.

Dacos, Nicole (1997): “Giulio Aquili, Andres de Melgar et leurs grotesques”. En: Dialoghi di Storia dell'Arte, 4/5, pp. 24-33.

Dacos, Nicole (2000): “De Castel Sant'Angelo à l'Alhambra, les stufette 'de Giulio Aquili'”. En: Festschrift für Konrad Oberhuber, Milán, pp. 107-114.

Dacos, Nicole (2007): “Julio y Alexandre. Grutescos italianos y cartografía flamenca en el Peinador de la Reina" En: Cuadernos de la Alhambra, 42, Granada, pp. 81-117.

Dacos, Nicole (2008): Las logias de Rafael. Madrid: Lunwerg.

Edwards, Nancy (1983): The renaissance "stufetta" in Rome. The circle of Raphael an the recreation on the Antique, University of Minnesota.

\footnotetext{
70 Gómez, 1912: 31.

${ }^{71}$ Este tema que será objeto de un trabajo posterior.
} 
García Mercadal, José (1972): Viajes por España. Vol. 3. Madrid: Alianza.

Gómez Moreno, Manuel (1919): "Los pintores Julio y Alejandro y sus obras en la Casa Real de la Alhambra". En: Boletín de la Sociedad Española de Excursiones. Arte. Arqueología. Historia. 27, Madrid, pp. 20-35.

Gómez Román, Ana María (1996): "Entorno a las habitaciones de Carlos V en la Alhambra”. En: Cuadernos de Arte de la Alhambra, 27, Granada, pp. 191-224.

Gnoli, Umberto (1911): "La quadreria civica di Rieti”. En: Bollettin d'Arte, 5, Roma, 325-340.

Herder, Gregory (1980): Antoniazzo Romano and his School. (Dissertation in the Department of Fine Arts summitted to the faculty of the Graduate School of Arts and Science in partial fulfillment of the requirements for the degree of Doctor of Philosophy at New York University).

Heredia Moreno, María del Carmen (2005): "Dibujos de Alonso Berruguete, Julio de Aquilis y Andrés de Melgar en la Fundación Lázaro Galdiano". En: Goya, 306, Madrid: pp. 132-144.

Keniston, Hayward (1980): Francisco de los Cobos. Secretario del Carlos V. Castilia. 1980.

López Torrijos, Rosa (1986): “La Escuela de Rafael y el bodegón español”. En: Archivo Español de Arte, 59, Madrid, pp. 33-52.

López Torrijos, Rosa (1987): "Los grutescos de Rafael y Udine en la pintura española. La estufa y la logia de Carlos V", Storia dell'Arte, 60, pp. 171-184.

López Torrijos, Rosa (1990): "L'influsso di Raffaello nella pittura spagnola del cinquecento". En: Fagiolo, Marcello e Madonna, Maria Luisa. Raffaello e l'Europa. Atti del IV corso internazionale di Alta cultura. Accademia Nazionale dei Lincei. Centro di studi sulla cultura e l'immagine di Roma. Istituto poligráfico e Zecca dello Stato. Roma. Librería dello Stato, pp. 702-713.

López Torrijos, Rosa (2000). "Las pinturas de la Torre de la Estufa o del Peinador de la Reina". En: AAVV. Carlos Vy la Alhambra. Granada: Patronato de la Alhambra y el Generalife, pp. 107-129.

Martínez Arancón, Ana/ Casas Santero, Elena/ Casas Santero, Ignacio (2013): Ideas y formas políticas de la Antigüedad al Renacimiento. Madrid: UNED.

Martínez Jiménez, Nuria: "Aprendiz de frescos. Noticia sobre la presencia de Gaspar Becerra en la estufa de la Alhambra”. En: Archivo Español de Arte, 41, 361, Madrid, pp. 63-67.

Martínez Elvira, Juan Ramón (1998): "Julio de Aquiles, el pintor italiano que vivió y murió en Úbeda (y II)". En: Ibiut, 17, 99, pp. 22-23.

Moreno Mendoza, Arsenio (2002): "La pintura en la ciudad de Úbeda en el siglo XVI: una aproximación histórica". En: Laboratorio de Arte, 15, Sevilla, pp. 83-109.

Mortari, Luisa (1960): Museo civico di Rieti. Roma: De Luca Editore.

Ovidio (1995): Metamorfosis. Madrid: Alianza.

Pacheco, Francisco (1956): El arte de la Pintura. Vol II. Madrid: Maestre.

Palomino, Antonio (1988): El museo pictórico y escala óptica. Vol. 3. Madrid: Aguilar.

Ramón-Laca Menéndez de Luarca, Luis (1999): "Plantas cultivadas en los siglos XVI y XVII en la Alhambra y el Generalife". En: Cuadernos de la Alhambra, 35, pp. 49-56.

Redondo Cantera, María José (2000): "La arquitectura de Carlos V y la intervención de Isabel de Portugal: palacios y fortalezas". En: Zalama Rodríguez, Miguel Ángel y Redondo Cantera, María José (Coords). Carlos V y las artes: promoción artística y familia imperial. Valladolid, pp. 67-106.

Redondo Cantera, María José (2013): "El palacio “imperial” Francisco de los Cobos en Valladolid”. En: Impronta, Cristina: El San Juanito de Úbeda restituido. Actas de la Conferencia Internacional. Florencia, pp. 229-248.

Ruiz Fuentes, Vicente Miguel (1992): "El pintor Julio de Aquilis: aportes documentales a su vida y obra”. En: Cuadernos de Arte de la Universidad de Granada, 23, Granada, pp. 83-96.

Russo, Giovanni (2014): Antoniazzo Romano. [Tesis de doctorado dirigida por el profesor Francesco Caglioti. Curso académico: 2013-14].

Sacchetti, Angelo (1916): “Antoniazzo, Marcantonio e Giulio Aquili a Rieti”. En: L'Arte,19, fasc.II. Roma, pp. 88-98.

Sacchetti, Angelo (1966): L'ultima opera di Marcantonio Aquili, Rieti: Tipografia Nobili.

Sánchez Cantón, Francisco Javier (1923): Fuentes literarias para la Historia del Arte Español. Madrid: Junta para Ampliación de Estudios e Investigaciones Científicas, Centro de Estudios Históricos [tomo V: Consejo Superior de Investigaciones Científicas, Instituto Diego Velázquez].

Torres Balbás, Leopoldo (1931): "Paseos por la Alhambra: La Tore del Peinador de la Reina o de la Estufa". En: Archivo español de arte y arqueología, 21, pp. 193-212.

Udine, Giovanni da (1987): I libri dei conti (1987). En: Dacos, Nicole; Furlan, Caterina; Argnelutti, Liliana; Bartolini, Elio (coords). Roma: Casamassima.

Vasari, Giorgio (2012): Le vite dei più eccellenti pittori,scultori e architetti. Roma: Grandi Tascabili Economici.Newton.

Villalón, Cristóbal de (1898): Ingeniosa comparación entre lo antiguo y lo presente.1539. Madrid: Sociedad de Bibliófilos Españoles.

Viñez Millet, Cristina (2007): "Viajeros en la Alhambra: el Peinador de la Reina". En: Cuadernos de La Alhambra, pp. $150-171$.

Fecha de recepción: 26-II-2018

Fecha de aceptación: 07-XI-2018 